\title{
PSICOLOGIA JURÍDICA E O CONTEXTO GRUPAL
}

\author{
Amanda Marchi do Amaral'; Alberto Francisco Carvalho Mallmann ${ }^{2}$; Cyndi \\ Naymayer Peres ${ }^{3 ;}$ Laísa Soltau Missio Pinheiro4; Camila dos Santos Gonçalves ${ }^{5}$
}

\section{RESUMO}

Dentre as inúmeras possibilidades de campos de atuação da psicologia, o âmbito jurídico se entrelaça de forma complexa e em crescimento. Nesse sentido, o presente trabalho tem como objetivo esclarecer algumas questões referentes à intersecção destes dois campos de estudo, destacando as funções, atribuições e contribuições da psicologia jurídica, dando destaque para as práticas grupais. $\mathrm{O}$ trabalho foi realizado por meio de uma pesquisa bibliográfica exploratória. A partir dela, foi possível elucidar acerca da intersecção da área de conhecimento do direito com a psicologia, possibilitando uma maior compreensão da atuação do psicólogo neste âmbito, das demandas mais frequentes e das possibilidades de intervenção, evidenciando a importância da realização de grupos.

Palavras-chave: Psicologia; Grupos; Psicologia Jurídica.

Eixo Temático: Atenção Integral e Promoção à Saúde (AIPS).

\section{INTRODUÇÃO}

Segundo Maciel, Brasil e Bastos (2013) a psicologia como área do saber busca compreender o indivíduo frente às suas subjetividades, incluindo seus processos psíquicos, princípios básicos, interações sociais e as diversas manifestações do comportamento humano. Já a Ciência Jurídica abarca as normas e regras instituídas para determinar e padronizar estes comportamentos, tendo o direito seu principal foco na resolução de problemas (IHERING, 2012)

A relação entre estes dois domínios do saber se dá de forma complexa, tendo o psicólogo atuante neste contexto seu lugar pouco delimitado, como destaca Cesca

\footnotetext{
${ }^{1}$ Acadêmica do Curso de Psicologia - UFN. amanda.marchi@ufn.edu.br

2 Acadêmico do Curso de Psicologia - UFN. mallmann.alberto@ufn.edu.br

${ }^{3}$ Acadêmica do Curso de Psicologia - UFN. c.peres@ufn.edu.br

${ }^{4}$ Acadêmica do Curso de Psicologia - UFN. laísa.missio@ufn.edu.br

${ }^{5}$ Professora substituta do Curso de Psicologia - UFSM. camila.gon.79@gmail.com
} 
(2004). O que se pode afirmar com precisão é a possibilidade de articulação de conhecimentos que ocorrem entre estas áreas, sendo imprescindível, em alguns casos, as formulações teóricas produzidas no campo de estudo psicológico quanto a fatores comportamentais, sociais, individuais e legais (MACIEL, BRASIL E BASTOS, 2013).

Dentro deste espectro muitas são as possibilidades de atuação do psicólogo jurídico, destacam-se a "investigação de fenômenos psicológicos, nos seus diferentes níveis de complexidades, apoio psicológico, mediação de conflitos, aconselhamentos, orientações, desenvolvimento de políticas públicas que atendam às necessidades sociais" entre outras (MACIEL, BRASIL E BASTOS, 2013, p. 24). Como desdobramento, as possibilidades de intervenções para cada demanda são diversas, e entre elas a realização de grupos ganha destaque. Neste contexto, o presente estudo tem como objetivo esclarecer o que concerne à psicologia jurídica, assim como as possibilidades de atuação do psicólogo jurídico e suas funções, dando ênfase à compreensão da realização de grupos como forma de intervenção.

\section{METODOLOGIA}

Este trabalho foi realizado a partir de uma pesquisa qualitativa exploratória, que segundo Gil (2002), tem caráter flexível e possui como principal objetivo a maior familiaridade com o tema abordado. Segundo o autor, este tipo de pesquisa pode ocorrer a partir do levantamento de fontes bibliográficas, físicas e digitais, como livros, artigos e publicação de periódicos.

Ao se realizar o levantamento, identificação e leitura de fontes adequadas é possivel obter uma variada gama de informações relacionadas ao tema proposto. $\mathrm{A}$ partir disso pode-se construir um texto claro e conciso, que de forma estruturada contemple os objetivos da pesquisa (GIL, 2002).

\section{RESULTADOS E DISCUSSÕES}

\subsection{PSICOLOGIA JURÍDICA}

Quando a psicologia jurídica foi institucionalizada, junto com o reconhecimento da psicologia como profissão, o psicólogo que trabalhava nesta 
área era responsável pela realização de testes psicológicos, de personalidade, laudos e pareceres técnicos. Com o passar dos anos e a consolidação deste campo de atuação, a psicologia jurídica passou a abranger novas demandas, como a resolução de conflitos e trabalhos com grupos interdisciplinares, como salientam Rodrigues et al. (2016).

Muñoz Sabaté (1980) classificou três correntes para existir uma psicologia jurídica, sendo elas: a psicologia do direito; a psicologia no direito; a psicologia para o direito. A psicologia do direito versa sobre elucidar a essência do fenômeno jurídico, fundamentação psicológica do mesmo, visto que, o direito está repleto de conteúdos psicológicos. Já a psicologia no direito diz respeito às estruturas das normas jurídicas enquanto estímulos para os indivíduos. As leis visam a causar algum efeito nas pessoas, para evitar certas condutas, existe um estímulo aversivo que vai ser realizado, para desestimular a realização do mesmo ou reincidência do mesmo. Na psicologia para o direito, esta entra como uma ciência para colaborar com o direito, colocando-se na mesma linha que a medicina legal, engenharia legal, entre outros, para dar sua assessoria aos objetivos do direito.

Segundo Maciel, Brasil e Bastos (2013) este campo de atuação tem sua importância pois é por meio da psicologia que a manifestação do comportamento humano, os processos psicológicos, assim como seus fatores sociais e individuais são compreendidos e relacionados com os saberes, muitas vezes padronizantes e determinantes, do direito. Nesse contexto a psicologia jurídica se caracteriza por ser uma área de atuação que direciona diferentes perspectivas sobre o comportamento humano, prezando pelos aspectos plurais e dinâmicos e seus desdobramentos no âmbito judicial (RODRIGUES et al., 2016).

Cabe ao psicólogo jurídico a responsabilidade de fazer uso de técnicas e procedimentos adequados para cada caso, sem deixar de lado a sensibilidade psicoterapêutica necessária para o exercício da profissão (FREITAS, 2011). Quanto a isso a profissional entrevistada reforça a ideia de que o psicólogo está a serviço da promoção de saúde, oferecendo uma prática humanizada às pessoas que buscam os serviços em questão. 
Referente às questões éticas que perpassam a atuação do psicólogo jurídico e as práticas grupais nesse contexto, são aplicadas as diretrizes inerentes à profissão, presentes no Código de Ética Profissional do Psicólogo. Para tanto há a necessidade de uma escuta qualificada e a importância do sigilo, como indica o Artigo 9ํㅡㄴ, sendo dever do psicólogo respeitá-lo por meio da confidencialidade. Deste modo também é importante ressaltar o que concerne ao Artigo 6ํㅡ e 12ํㅡ do Código de Ética, visto que tanto a prática grupal como outros trabalhos realizados no meio jurídico contam com a atuação de profissionais de diferentes áreas. Estes Artigos enfatizam que o profissional psicólogo deve compartilhar e registrar, com a equipe multidisciplinar, apenas informações necessárias e relevantes para a realização do trabalho (CFP, 2005).

\section{2 ÁREAS DE ATUAÇÃO DO PSICÓLOGO RELACIONADO AO DIREITO}

As áreas de atuação do Psicólogo que englobam ramos do Direito, como Direito da Criança e do Adolescente, Direito Civil, Direito da Família, Direito Penal e Direito do Trabalho, estão ligadas às práticas e ações do Psicólogo Jurídico, quais se diferenciam conforme o requerimento do Juiz e a demanda suplicada (LAGO et al., 2009). Evidencia-se uma predominância acerca dos Processos de Avaliação Psicológica na área jurídica, por meio de testes, avaliações e entrevistas, tendo em vista o levantamento de dados e assimilações para com diagnósticos. Essas atividades implicam em produção de laudos e relatórios, assim como indicações sobre soluções para as questões requeridas (LAGO et al., 2009).

Nas diversas instituições do direito, são campos de atuação do Psicólogo Jurídico o direito de família, da criança e do adolescente, abrangendo questões relacionadas a divórcios, disputa de guarda, regulamentação de visitas, adoção, destituição do poder familiar, entre outros. Além disso, direitos trabalhistas, adolescentes e atos infracionais, interdições, vitimologia e psicologia do testemunho configuram-se como temas relevantes que necessitam da interferência do saber psicológico (LAGO et al., 2009). Outra área de atuação do profissional é a mediação ao qual versa sobre o ato de mediar, sendo esta um meio de intervir com o fim de se 
obter um acordo entre pessoas físicas ou jurídicas, consistindo assim numa aproximação entre as partes interessadas (GUIMARÃES, 2016).

Esse campo de atuação é relativamente novo e ainda está em expansão tanto como esfera de atuação, quanto do conhecimento da população em geral que ainda não tem ciência de sua existência. Sempre foi vinculado ao direito mas, a cada dia apresenta um terreno fértil para ser desempenhado pelos psicólogos. Estes devem servir como facilitadores, conseguindo criar um canal de conversa entre os envolvidos, sempre diferenciando seu papel para um magistrado. O mediador, não pode interferir diretamente na lide, entretanto, deve ajudar a encontrar uma saída ou uma alternativa que possa vir a beneficiar as duas partes. Para tal, este profissional deverá se utilizar de várias fontes de conhecimento como, a própria psicologia, direito, teorias e técnicas de negociação entre outros, para compreender a situação e dar condições para que a necessidades dos envolvidos venham a ser satisfeitas sem nenhum prejuízo oriundo desta negociação (CFP, 2006).

Ainda, um campo de essencial atuação do psicólogo é no direito de família, neste, o profissional está capacitado para a mediação, sendo que a literatura internacional sobre o tema, juntamente com a graduação na área, apresentam uma base sólida para a viabilização desta função, assim podem e devem ser utilizados nas audiências (OLIVEIRA; THERENSE, 2017). Assim, os profissionais podem atuar prestando serviços de orientação psicológica a família, fomentando o envolvimento dos membros na resolução dos conflitos e na reorganização do cotidiano familiar após o divórcio; oferecimento de grupo de apoio pré/pós audiência, buscando alternativas úteis para os novos desafios do cotidiano (SILVA, 2011).

No que tange a separação de casais, também podem ajudar na disputa da guarda e na organização das visitas. Cabe-se ressaltar que a maioria dos processos de separação e divórcio ocorrem de forma litigiosa, ao qual é objeto de controvérsia, sendo que os envolvidos não chegam a acordo nenhum. Assim, o psicólogo poderá atuar como mediador nesta contenda, compreender as duas partes, descobrindo o que impede eles de realizar a separação. Também pode orientar que esses indivíduos busquem um tratamento psiquiátrico ou psicológico, dependendo do caso em questão (LAGO et al., 2009). 
Existe ainda um campo por vezes inexplorado, os casos de adoção. Neste, os psicólogos assumem a função de disponibilizar a Justiça um parecer científico, seja por meio de laudos, avaliações psicológicas ou demais instrumentos. Assim, o papel do psicólogo decai sobre transmitir sua visão técnica ao magistrado, com o intuito de diminuir os erros oriundos da falta de análise dos envolvidos no processo. Ademais, o profissional deve auxiliar as pessoas envoltas ao processo da adoção, auxiliando no entendimento da vontade de adotar e nas questões emocionais que cercam o processo (SILVA; TOKUDA, 2018).

Neste sentido, as áreas de atuação da psicologia no contexto jurídico estão relacionadas às por demandas oriundas dos processos judiciais. É importante considerar que existe uma interdisciplinaridade na atuação neste campo, onde várias áreas do conhecimento se unem para prestar um atendimento a esses indivíduos, cada um em seu ramo do conhecimento, pois com essa pluralidade consegue-se dar uma atenção especial.

\subsection{ATUAÇÃO COM GRUPOS NO CONTEXTO JURÍDICO}

Conforme Clemente (1998), a psicologia jurídica é o estudo do comportamento das pessoas e dos grupos enquanto tem necessidade de desenvolver-se dentro de ambientes regulados juridicamente, assim como da evolução dessas regulamentações jurídicas ou leis enquanto grupos sociais se desenvolvem neles. Nesse contexto, o trabalho do Psicólogo em grupos inicia quando há uma rede de pessoas que demandam semelhantes problemas.

A partir de então, é necessário investigar acerca da população com que se vai trabalhar, obter informações, definir objetivos e uma proposta de trabalho, programar procedimentos, encontros e intervenções, divulgar o grupo, pensar a quantidade de participantes, se será designado aberto ou fechado, fazer combinações, como local a ser realizado, duração e frequência dos encontros, e pensar e agir de modo uníssona (CASETTO, 2013; YALOM; LESZCZ, 2006).

O Núcleo de Práticas Jurídicas (NPJ) da Universidade Franciscana é um potencial campo de práticas interdisciplinares para estudantes de diferentes cursos para a realização de estágios e práticas dos conteúdos teóricos, e oferece de forma 
gratuita atendimento à comunidade. Como suporte para a população com demandas nas áreas de Famílias, Trabalhista e Cíveis, Responsabilidade Civil e Defesa do Consumidor.

Nesse espaço são realizados grupos voltados a mediação de conflito ou superendividamento. O primeiro é uma ferramenta de resolução de um conflito entre pessoas na presença de um terceiro, que seria o mediador, este com preparação adequada, auxiliará na comunicação e no levantamento de soluções entre as partes (SALES, 2016). O segundo é explicado a partir da Lei $n^{0} 14.181 / 2021$ em seu artigo Art. 54-A, $\S 1^{\circ}$ :

"Entende-se por superendividamento a impossibilidade manifesta do consumidor, pessoa natural, de boa-fé, pagar a totalidade de suas dívidas de consumo, exigíveis e vincendas, sem comprometer seu mínimo existencial, nos termos da regulamentação". (BRASIL, 2021)

Os grupos são divulgados em sites, jornais e televisão. Os integranteschegam por livre demanda ou são convidados e encaminhados para o projeto quando procuravam assistências relativas a empecilhos acerca de despesas. $O$ enfoque temático tende a ser sobre a situação de superendividamento, sendo debatido seu significado para cada pessoa e possiveis medidas que poderiam ser tomadas para a resolução do problema, assim como, podem ser tratados assuntos sobre organização de dívidas e direito do consumidor.

É possível que apareçam demandas relacionadas à saúde mental e adoecimento psíquico das pessoas que vivenciavam essas circunstâncias. Alguns aspectos devem ser observados, como por exemplo, a compulsão por compras, o que poderia resultar em endividamento, e outros problemas de saúde e dificuldades físicas.

É importante que os grupos sejam abertos e não obrigatórios, para assim possibilitar que os participantes possam escolher ir ou não, dado que não é exigido frequência (FURLAN; CAMPOS, 2010). Outra possibilidade de grupo pode ser para a preparação para o mercado de trabalho, que organizava e preparava os seus integrantes para o mercado de trabalho, visto que muitas pessoas que se enocntram com questões de endividamento também podem estar fora do mercado de trabalho. 
Pode ser oferecido na proposta de grupo fechado, isto é, programado do início ao fim e com uma proposta terapêutica definida, com limites de encontros e participantes, exigindo destes continuidade e frequência (FURLAN; CAMPOS, 2010).

Furlan e Campos (2010) salientam que o local dos grupos deve ser acolhedor, concedendo o sigilo e as cadeiras dispostas em círculo para que os participantes se relacionem e se olhem. Alguns cuidados importantes referem-se ao ambiente, qual era um espaço propício e com material organizado, bem como com profissionais preparados e capacitados para coordenar o grupo, dispondo da autorização dos participantes através do contrato inicial, que especifica o funcionamento do processo a ser realizado e a liberdade destes em participar se desejar.

Por fim, há outros grupos possíveis de serem realizados no campo jurídico. No que se refere ao direito de família, é relevânte a realização de trabalhos neste contexto devido a complexidade das questões tratadas, como processos de separação, violência, guarda dos filhos, entre outros. Ainda, um dos obstáculos para essa prática ser realizada seria a parte legal, visto que, não consta em lei, deste modo, não há obrigatoriedade para a mesma, e assim as pessoas acabam por não executar essa atividade, mas a realização desta traria inúmeros benefícios à população.

\section{CONCLUSÃO}

A partir do objetivo do presente trabalho, foi possível esclarecer desde o início sobre a atuação da psicologia na área jurídica, não apenas com o profissional sendo responsável na realização de testes psicológicos, de personalidade, laudos e pareceres técnicos, mas a sua ampiação e consolidação em outras esferas de ação, em que este passou a abranger novas demandas, como a resolução de conflitos e trabalhos com grupos interdisciplinares. Os campos de atuações desses profissionais relativamente interligados aos do campo do direito destinam-se a prestar os seus serviços no Direito da Criança e do Adolescente, o Direito Civil, o Direito da Família, o Direito Penal e o Direito do Trabalho, caracterizando-se principalmente por sua variedade e complexidade de demandas. 
Com base no exposto, pode-se observar a importância dos grupos nas práticas junto ao sistema jurídico, pois possibilita aos participantes um cuidado, além de suporte e esclarecimentos sobre o assunto, e ainda, acerca da saúde mental. Inclusive, a mediação no contexto do direito da família e a importância de trabalhos nessa área, também se mostrou uma área em crescimento.

Assim sendo, esta pesquisa bibliográfica, auxiliou na compreensão do campo de atuação do psicólogo jurídico e os grupos inseridos nesta área. Portanto, a continuidade de pesquisas a respeito do âmbito jurídico e suas peculiaridades, bem como o contato com o trabalho do psicólogo nos grupos, se constitui como fundamental para os estudantes e profissionais da área, dado a importância social intrínseca a este âmbito.

\section{REFERÊNCIAS}

BRASIL. Lei no 14.181, de 1ำ de Julho de 2021. Brasília, Distrito Federal, 1 $^{\circ}$ de julho de 2021.

CASETTO, S. J. Notas sobre grupos. In: CAPOZZOLO, A.A; CASETTO, S.J.; HENZ, A. O. Clínica comum: itinerários de uma formação em saúde. São Paulo: Hucitec, 2013, p.290-298.

CESCA, T. B. O papel do psicólogo jurídico na violência intrafamilar: possíveis articulações. Psicologia \& sociedade. v. 16, n. 3, p. 41-46, 2004.

CLEMENTE, M. Fundamentos de la psicologia jurídica. Madrid: Piramide, 1998,

CONSELHO FEDERAL DE PSICOLOGIA. Código de Ética Profissional do Psicólogo, 2005. Disponível em: <https://site.cfp.org.br/legislacao/codigo-de-etica/>. Acesso em: 12 novembro 2019.

CONSELHO FEDERAL DE PSICOLOGIA. Jornal do Federal. Jornal do Conselho Federal de Psicologia, 2006. Disponível em: <https://site.cfp.org.br/wpcontent/uploads/2006/11/jornal federal 85.pdf>. Acesso em: 17 de novembro de 2019. 
FREITAS, M. A. Psicologia Jurídica e Psicologia Forense: Aproximações e distinções. Revista de Psicoanálisis y estudios culturales, (10), 1-1, 2011.

FURLAN, P.G; CAMPOS, G.W.S. Os grupos na Atenção Básica à Saúde. In: Cadernos Humaniza SUS, V.2, Ministério da Saúde, 2010, p. 106-115.

GIL, A. C. Como Elaborar Projetos de Pesquisa. 4. ed. São Paulo: Atlas, 2002.

GUIMARÃES, Deocleciano Torrieri. Dicionário Técnico Jurídico. São Paulo: Riddel, 2016.

IHERING, Rudolf von. A luta pelo direito. São Paulo: Hunter Books, 2012.

LAGO, V. M.; PALOMA, A.; TEIXEIRA, P. A.; ROVINSKI, S, L R.; BANDEIRA, D. R. Um breve histórico da psicologia jurídica no Brasil e seus campos de atuação. Campinas: Estudos de Psicologia, 2009, p. 483-491. Disponível em: $<$ http://www.scielo.br/scielo.php?script=sci arttext\&pid=S0103166X2009000400009\&lang=en>. Acesso em: 17 outubro 2019.

MACIEL, S. K.; BRASIL, V.; BASTOS, V. Psicologia jurídica. Palhoça: UnisulVirtual, 2013.

MUÑOZ, Sabaté, L. Métodos y elementos para una psicología jurídica. En L. Muñoz, R. Bayés y F. Munné (eds.), Introducción a la psicología jurídica (pp. 15-46). México: Trillas, 1980.

OLIVEIRA, Edvânia da Costa; THERENSE, Munique. A atuação do psicólogo no centro judiciário de solução de conflitos e cidadania (cejusc): relato de experiência em Manaus. In: LEVI, M. C. H. et al. Psicologia Jurídica e Direito de Família Para além da perícia psicológica. Manaus: Editora Universitária, 2017.

RODRIGUES, C.A. et al. A prática do psicólogo jurídico no contexto da dinâmica familiar. O portal do psicólogo, 2016. Disponível em: $<$ https://www.psicologia.pt/artigos/textos/TL0401.pdf>. Acesso em: 17 outubro 2019. 


\section{QUFN}

SALES, L. M. M. A mediação de conflitos: lidando positivamente com as emoções para gerir conflitos. Fortaleza: Pensar - Revista de Ciências Jurídicas, 2016, v. 21, n. 3, p. 965-986. Disponível em: <https://periodicos.unifor.br/rpen/article/view/5289>. Acesso em: 18 nov. 2019.

SILVA, D. M. P. da. Mediação e guarda compartilhada: Conquistas para a família. Curitiba: Juruá, 2011.

SILVA, Letícia Carvalho; TOKUDA, André Masao Peres. A função do psicólogo dentro do processo adotivo. Revista Conexão Eletrônica, Três Lagoas, MS, ano 2018, v. $15, \quad$ n. 1 , p. 1642-1653, 2018. Disponível em: < http://revistaconexao.aems.edu.br/edicoes-anteriores/2018/2018/ciencias-sociaisaplicadas-e-ciencias-humanas-6/>. Acesso em: 18 de novembro 2019.

YALOM, I.D.; LESZCZ, M. Psicoterapia de grupo: teoria e prática. Porto Alegre: Artmed, 2006, p. 227-247. 